\title{
The effect of dynamic vulcanization on the morphological and mechanical properties of the toughened poly (lactic acid)/epoxidized natural rubber
}

\author{
Nur Amira Sahirah Abdullah a , Zurina Mohamad b, ${ }^{\text {* }}$ \\ a Department of Bioprocess and Polymer Engineering, Universiti Teknologi Malaysia, 81310 UTM Johor Bahru, Johor Malaysia \\ ${ }^{b}$ Faculty of Engineering, School of Chemical and Energy Engineering, Universiti Teknologi Malaysia, 81310 UTM Johor Bahru, Johor, Malaysia \\ * Corresponding author: r-zurina@utm.my
}

\section{Article history}

Received 21 Mac 2018

Revised 1 June 2018

Accepted 2 July 2018

Published Online 3 September 2018

Graphical abstract
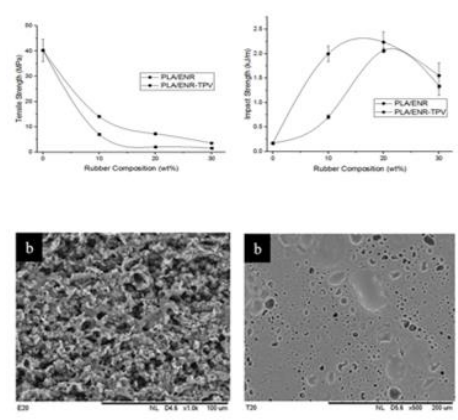

\begin{abstract}
Poly (lactic acid)/epoxidized natural rubber (PLA/ENR) blends were prepared using a counterrotating twin-screw extruder. The ENR was compounded with $3 \mathrm{phr}$ of N, N'-mphenylenebismaleimide (HVA-2) as a crosslinking agent for the dynamically vulcanized blend. The aim of this study is to determine the effect of the unvulcanized and dynamically vulcanized of ENR on the properties of PLA/ENR blends. The PLA/ENR blends were prepared with the various composition of ENR (0 wt\% to $30 \mathrm{wt} \%$ ). The morphology and mechanical properties of the blends were investigated by using scanning electron microscope (SEM), tensile test, and impact test. The unvulcanized blend produced a co-continuous morphology of PLA and ENR and the dynamically vulcanized blend shows the dispersed ENR rubber particles in PLA continuous matrix. The tensile strength of the unvulcanized and dynamically vulcanized blends drop with the increasing amount of ENR content. The impact strength of both systems shows the maximum value at $20 \mathrm{wt} \%$ of ENR content. The dynamically vulcanized PLA/ENR blend shows a better tensile strength and impact strength compared with the unvulcanized blend.
\end{abstract}

Keywords: Poly (lactic acid), epoxidized natural rubber, dynamic vulcanization, HVA-2

\section{INTRODUCTION}

Nowadays, world-wide are produced over 200 million tons of plastics each year and $40 \%$ of them are used in short-life products such as packaging (Xu et al., 2016). The plastics that commonly produced are polyethylene includes high density polyethylene and low density polyethylene (29.6\%), polypropylene (18.9\%), polystyrene (7.1\%), polyvinyl chloride (10.4\%), polyethylene terephthalate (6.9\%) and other types of plastic that represent about $19.7 \%$ which are approximately $90 \%$ of the total plastic production worldwide. Most of the plastics are known as "hard to degrade" materials (Li et al., 2016; Saad et al., 2016). This rapid growth of the plastic production leads to the serious environmental pollution due to half of them are disposed to the environment within a short period (Moura et al., 2012). Due to the environmental concerns and sustainable issues, the plastic wastes problem can be solved by using the bio-based polymer to substitute the conventional petroleum-based polymer which is easily degradable and it is considering as an environmentally friendly material. The biobased polymer known as a biodegradable polymer. The properties of the biodegradable polymer such as mass, molecular weight, and strength may degrade with time when scavenge by a microorganism and will produce by-products such as carbon dioxide, water, inorganic compounds or biomass (Xu et al., 2016; Gorrasi et al., 2013).
Poly (lactic acid) (PLA) is one of the promising and commercially available biodegradable polymer material in the market that can replace the conventional petroleum-based polymer (synthetic polymer) in packaging and other engineering applications. PLA is a biodegradable aliphatic polyester that produced via fermentation of the carbohydrate from the renewable agriculture sources such as corn (Auras et al., 2010; Laurence, 2012; Aghjeh et al., 2015). PLA is highly transparent that behaves as glassy and brittle material that exhibit the tensile strength of $30 \mathrm{MPa}$ to $50 \mathrm{MPa}$ with an elongation at break of $1 \%$ and $7 \%$ depends on its molecular weight. The tensile modulus of the PLA in the range of $2 \mathrm{GPa}$ to $4 \mathrm{GPa}$ (Xu et al., 2016; Yang et al., 2015; Ebadi-Dehaghani et al., 2015). PLA has the mechanical properties limitation such as poor toughness (for the applications that need plastic deformation at high-stress level) and thermally unstable (Xu et al., 2016; Ebadi-Dehaghani et al., 2015). To overcome the brittleness of the PLA, there are several methods that can be used such as processing manipulation, copolymerization, and blending with other polymer (thermoplastic or elastomeric polymer) (Zhang et al., 2013).

In fact, the epoxidized natural rubber (ENR) is the elastomeric material that has been modified from the natural rubber (NR) and consists of the double functionality of crosslinking which is an epoxy group and double bond that makes ENR a polar material. ENR can be used as a toughening agent to the rigid polymer composite since ENR has high impact strength and excellent resistance to puncture and tear 
(Hazwani Syaza Ahmad et al., 2016; Mohamad et al., 2013). Pongtanayut et al. (2013) state that there is partially compatibility between PLA and ENR as compared to PLA/natural rubber (NR) at $20 \mathrm{wt} \%$ of the rubber composition. The PLA/ENR blend system shows a very fine ENR particle dispersion which acts as the second phase in the PLA matrix. The ENR also act as stress concentrators that enhance the fracture energy absorption of brittle PLA and resulting in improving the toughness of the PLA but tensile strength had decreased due to the ductile properties. According to Zhang et al. (2013), the impact strength and elongation at break of $20 \mathrm{wt} \%$ ENR50/PLA and ENR20/PLA were increased as compared to pure PLA and this is due to the good interfacial adhesion between PLA and ENR. The addition of the ENR into PLA matrix, have reduced the tensile strength and modulus. Akbari et al. (2014) reported that the addition of $20 \mathrm{wt} \%$ of ENR into the PLA/talc composites improved the impact strength due to the enhancement of PLA chains mobility by ENR.

Wang et al. (2015), shows that the dynamic vulcanization of PLA/ENR in the presence of dicumyl peroxide (DCP) as a curing agent have improved the impact strength and elongation at break of the PLA while the tensile strength shows decreasing trend. Thongpin et al. (2012), stated that the tensile strength and modulus of the dynamically vulcanized PLA/ENR/OMMT increases while elongation at break decreases as the OMMT loading increases. Zurina et al. (2008) investigated on ENR50/EVA blend containing HVA-2 as curing agent and proved that the interfacial adhesion, compatibility and tensile strength improved with the addition of HVA-2.

Besides sulphur and DCP, HVA-2 being used as a crosslinking agent to vulcanize ENR. The advantage of using HVA-2 as a crosslinking agent is due to the HVA-2 able to vulcanize rubber in the absence of other catalyst and free radicals source. It's also free from residual chemicals such as zinc oxide, stearic acid and nitrosamines where they possess low cytotoxicity. HVA-2 also have a less rubbery protein that causes allergic responses. HVA-2 also acts as multifunctional radical acceptors to promote a combination of dissimilar polymer radicals to produce a copolymer and create sufficient copolymer to reduce interfacial tension (Hassan et al., 2003; Ismail Halimatuddahliana et al., 2005; Kahar et al., 2013). The objective of this research is to produce toughened PLA with the improved toughness of PLA matrix. - The effect of the blend compositions and dynamically vulcanized ENR on the properties of the PLA/ENR was reported in this work.

\section{EXPERIMENTAL}

\section{Materials}

The poly (lactic acid) grade 3052D was supplied by Innovative Pultrusion Sdn. Bhd., Malaysia. The epoxidized natural rubber (ENR), grade "Epoxyprene 50" with 50\% epoxidization level was supplied by Malaysia Rubber Board, Malaysia. The crosslinking agent N-N'-mphenylene dimaleimide (HVA-2) was obtained from DuPont Dow Elastomer.

\section{Samples Preparation}

PLA was dried in the oven at $40^{\circ} \mathrm{C}$ for 24 hours prior to compounding. The PLA and ENR were compounded by using corotating twin-screw extruder with a screw speed of $50 \mathrm{rpm}$. The barrel temperature profile used during mixing is $150^{\circ} \mathrm{C}$ to $170^{\circ} \mathrm{C}$ from the hopper to the die zone. The ENR content was varied from $10 \mathrm{wt} \%$ to $30 \mathrm{wt} \%$. The extrudates were collected from the die. Then, the blend material was moulded into sheets of $1 \mathrm{~mm}$ and $5 \mathrm{~mm}$ in thickness using the hot press at $170^{\circ} \mathrm{C}$ for $10 \mathrm{~min}$ with a pressure of $110 \mathrm{~kg} / \mathrm{cm}^{2}$ The samples were cut into the dumbbell and rectangular shape for further testing and characterization.

For dynamic vulcanization samples, a two-step mixing process was performed by first compounding the ENR with 3 phr of HVA-2 by using two roll mill. In the second step, the ENR with HVA-2 was melt mixed with PLA in the co-rotating twin-screw extruder with the same condition. Table 1 shown the blend formulation for the unvulcanized (PLA/ENR) and dynamically vulcanized (PLA/ENRTPV) blend respectively.
Table 1 The blend formulation for the PLA/ENR and PLA/ENR-TPV

\begin{tabular}{ccccc} 
Sample & $\begin{array}{c}\text { PLA } \\
(w t \%)\end{array}$ & $\begin{array}{c}\text { ENR } \\
(w t \%)\end{array}$ & $\begin{array}{c}\text { ENR-TPV } \\
(w t \%)\end{array}$ & $\begin{array}{c}\text { HVA-2 } \\
(\mathbf{p h r})\end{array}$ \\
\hline PLA & 100 & - & - & - \\
\hline P90E10 & 90 & 10 & - & - \\
\hline P80E20 & 80 & 20 & - & - \\
\hline P70E30 & 70 & 30 & - & - \\
\hline P90T10 & 90 & - & 10 & 3 \\
\hline P80T20 & 80 & - & 20 & 3 \\
\hline P70T30 & 70 & - & 30 & 3 \\
\hline
\end{tabular}

\section{Testing and Characterization}

\section{Mechanical Properties}

The tensile test was performed using a Tensile Tester EZ 20kN Llyord to determine the tensile strength, tensile modulus, and elongation at break of the samples. The test was carried out according to ASTM D638. The specimen was tested at a cross-head speed of 10 $\mathrm{mm} / \mathrm{min}$.

The Izod impact test was carried out by using impact testing machine and the samples were tested at ambient temperature. The testing was performed according to ASTM D256 and the impact strength value was recorded. The dimension of the sample is $65 \mathrm{~mm}$ length $\times 12.7 \mathrm{~mm}$ width $\times 3 \mathrm{~mm}$ thick.

\section{Scanning Electron Microscope (SEM)}

The morphology of impact fractured surface was analyzed using a scanning electron microscope (SEM), SEM Philips ZL40. To avoid the electrostatic charging, the samples were coated with platinum. The samples were etched with toluene for unvulcanized and nitric acid for the dynamically vulcanized sample to selectively etched out rubber phase.

\section{RESULTS AND DISCUSSION}

\section{Mechanical Properties}

Tensile strength, and tensile modulus of PLA/ENR and PLA/ENR-TPV blends are presented in Fig. 1. The tensile strength and tensile modulus for both PLA/ENR and PLA/ENR-TPV blends decrease as rubber composition increased where this finding consistent with a previous study (Zhang et al., 2013; Akbari et al., 2015). This decrement of the strength may depend on a few factors such as the elastomeric nature of the ENR, dispersion of ENR and surface interaction between PLA and ENR. The ENR has the relatively low strength and modulus with bulky pendant groups in its chains as compared to pure PLA. The PLA/ENR-TPV blends system showed higher values in tensile strength and modulus as compared to PLA/ENR blends system for all rubber composition. This increment values of the PLA/ENR-TPV is due to the crosslinking of the ENR with HVA-2. The addition of HVA-2 in the ENR has promoted the intramolecular and intermolecular linkage in ENR phase. Besides, HVA-2 was used in this system as a way to compensate for the strength deterioration caused by incorporation of ENR. From the observation, HVA-2 is capable to be used in order to improve the blends properties (Kahar et al., 2013).

Addition of the ENR and ENR-TPV lead to the decreases of tensile modulus especially at the higher content of rubber since the ENR has a soft characteristic and relatively low modulus. The increment of the tensile modulus has been seen in the ENR-TPV system where indicating the rise of the blends stiffness. The HVA-2 is responsible for forming crosslink or grafted structure and increase the dimensional stability of the ENR phase where the crosslink of the ENR can improve the blends modulus. Other than that, crosslink of the ENR and HVA-2 also can prevent the polymer chain to slip and resulting in more rigid polymer blend (Kahar et al., 2013, Ismail Halimatuddahliana et al., 2005). 

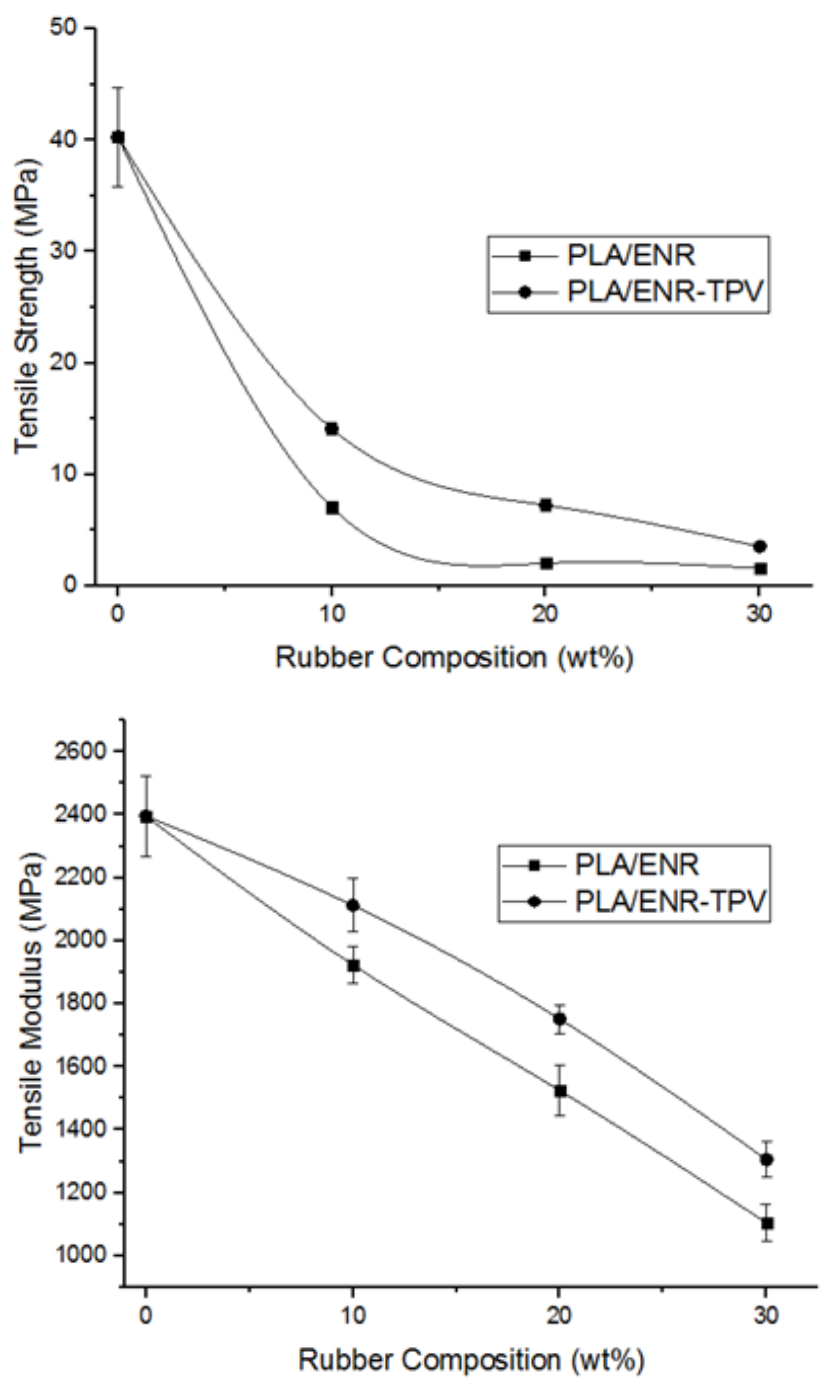

Fig. 1 Tensile strength and tensile modulus of pure PLA, PLA/ENR, and PLA/ENR-TPV blends.

The elongation at break and impact strength of PLA/ENR and PLA/ENR-TPV blends are shown in Fig. 2. The impact strength of both blend system increases from $0 \mathrm{wt} \%$ to the $20 \mathrm{wt} \%$ of the rubber composition and starting to drop at $30 \mathrm{wt} \%$ of the rubber composition. The PLA/ENR and PLA/ENR-TPV showed the highest impact strength which is $2.07 \mathrm{~kJ} / \mathrm{m}$ and $2.24 \mathrm{~kJ} / \mathrm{m}$ respectively at $20 \mathrm{wt} \%$ of the rubber composition. ENR and ENR-TPV are effective in increasing the toughness but decreasing in stiffness. The existent of crosslink or grafted between PLA and rubber generate a higher degree of chain entanglement which leads to the increasing of impact strength (Akbari et al., 2014; Wang et al., 2015; Thongpin et al., 2012). The elongation at break of PLA/ENR and PLA/ENR-TPV blend dropped with the increase in ENR composition. It may be due to the greater interaction between PLA and ENR and ENR-TPV via chemical reaction where the blends formed a crosslink or grafted structure that can reduce the elongation at break (Akbari et al., 2014; Tarinee Nampitch et al., 2010). The elongation at break of the PLA/ENR-TPV blends was greater than PLA/ENR blends. This indicates that the crosslinking of ENR in the PLA/ENR-TPV system by HVA-2 has imparted higher elongation at break of the material.
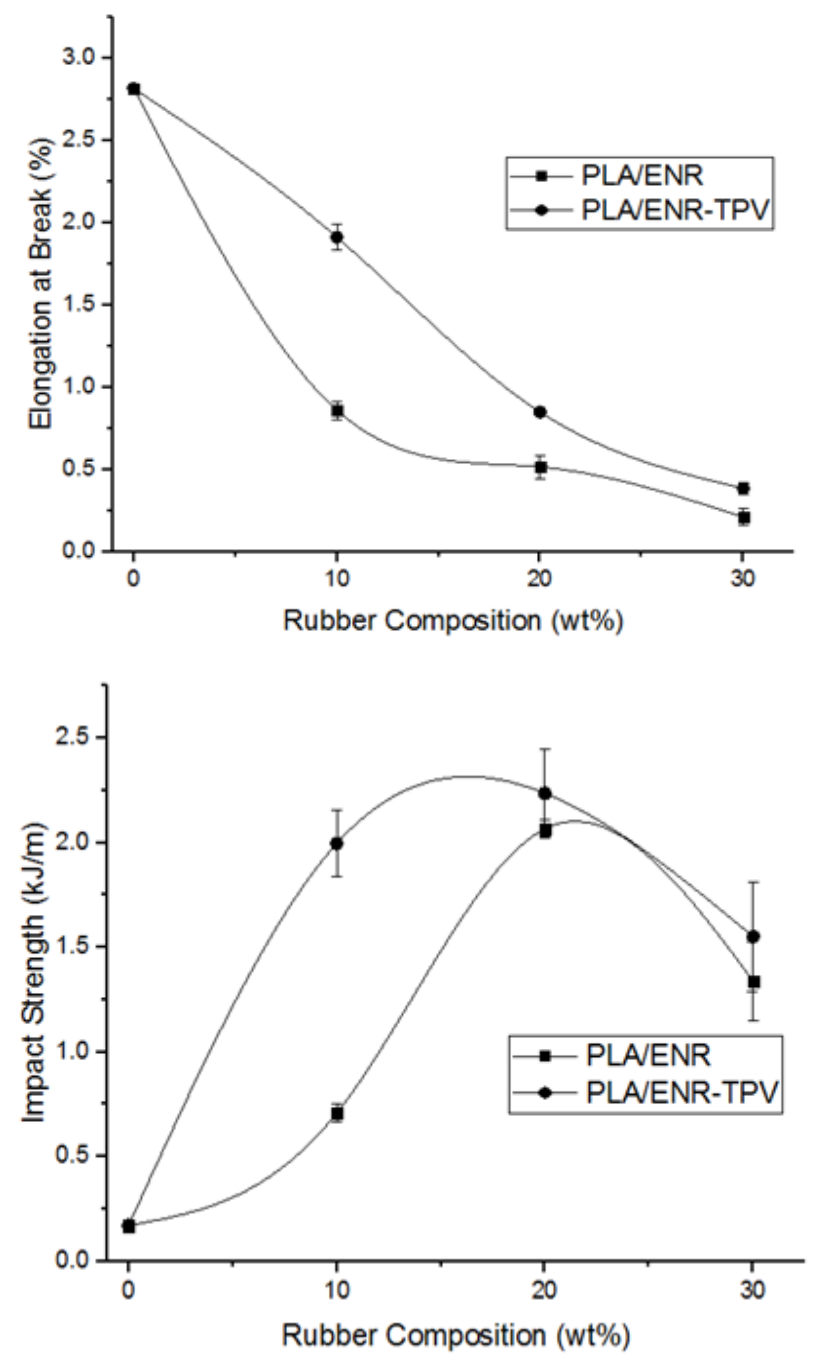

Fig. 2 Elongation at break and impact strength of the PLA/ENR and PLA/ENR-TPV blends.

\section{Morphological Study (SEM)}

Fig. 3 show the SEM images of impact fractured surfaces of PLA/ENR blends at different ENR content. The PLA/ENR blend shows a co-continuous morphology with a coarse surface. This can be considered a partially compatible with ENR and PLA matrix. The continuous structure of ENR has increased the molecular entanglement and network structure that lead to the increase of the impact strength. During the fracture process, the fracture crack ran along the interface between the PLA matrix and ENR particles which resulting the crack energy produced can be absorbed and dissipated by the ENR phase.

Fig. 4 displays the SEM images of impact fractured surfaces of PLA/ENR-TPV blends at $10 \mathrm{wt} \%, 20 \mathrm{wt} \%$ and $30 \mathrm{wt} \%$ of ENR composition. The PLA/ENR-TPV blends showing the morphology of ENR rubber particles dispersed in continuous PLA matrix. The rubber particles in the blend with $20 \mathrm{wt} \%$ ENR content showing smaller rubber particles (Fig. 4 (b)) as compared with other blends ratio. These small rubber particles provide a higher surface area for better interfacial interaction between the components and facilitate a better stress concentration and stress transfer in the blends thus lead to the highest impact strength value and contributing to the high toughness. At $30 \mathrm{wt} \%$ of ENR content, the impact strength dropped and this may be due to the formation of bigger ENR rubber particles (Fig. 4 (c)). 

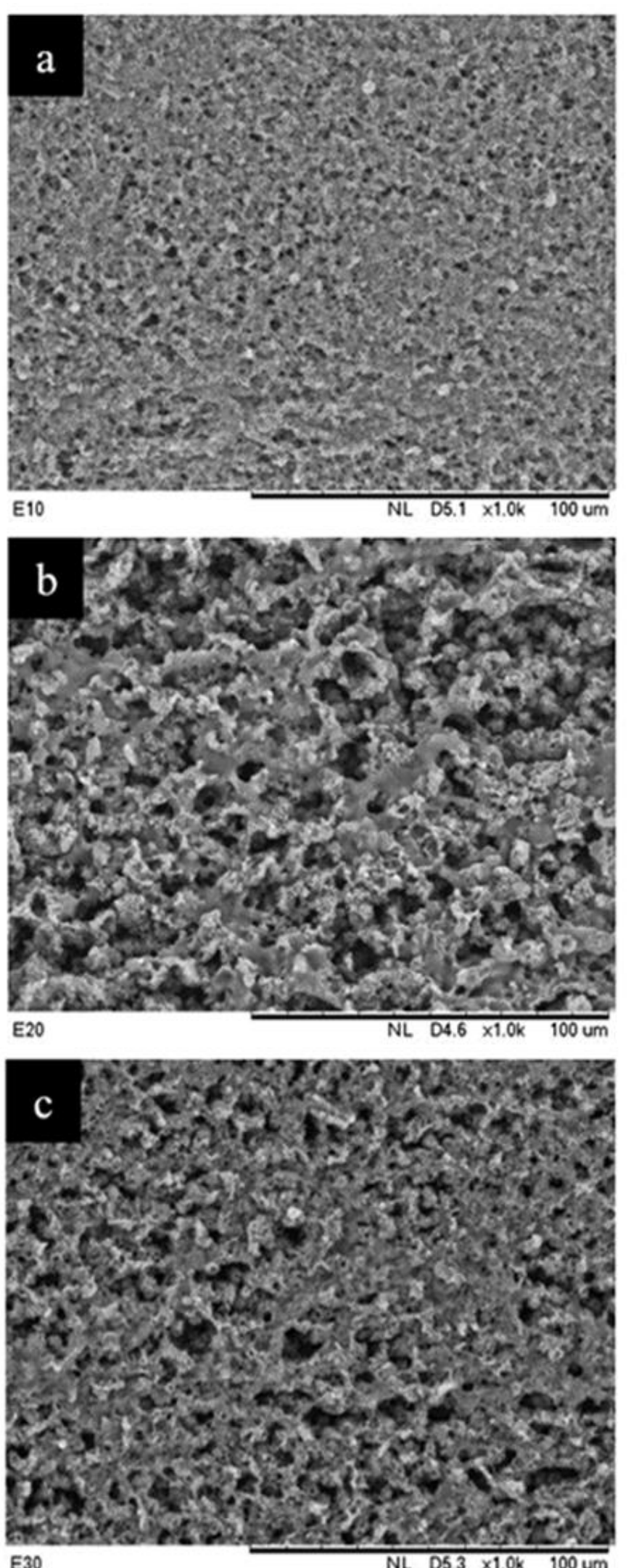

Fig. 3 SEM images of impact fractured surface for PLA/ENR (a) 10 wt $\%$ (b) $20 \mathrm{wt} \%$ (c) $30 \mathrm{wt} \%$ ENR composition.
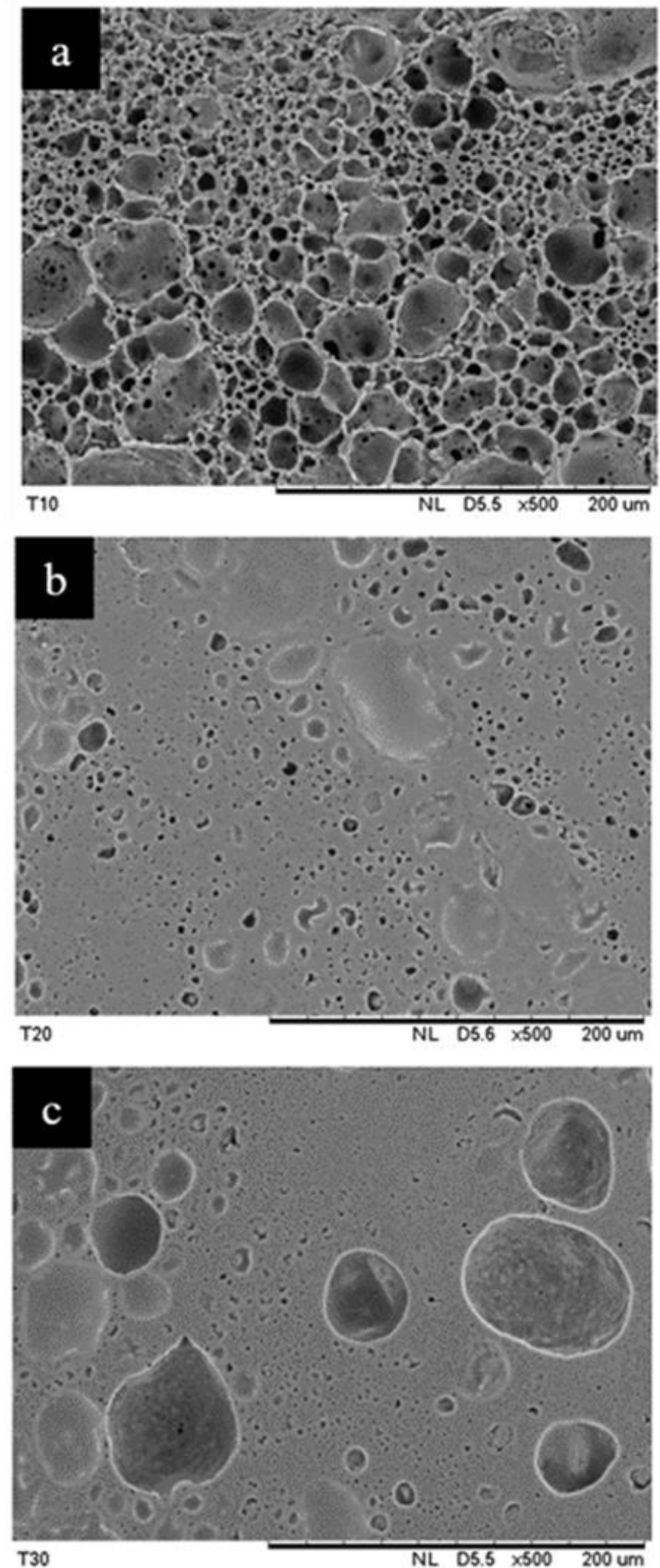

Fig. 4 SEM images of impact fractured surface for PLA/ENR-TPV (a) $10 \mathrm{wt} \%$ (b)20 wt\% (c) $30 \mathrm{wt} \%$ ENR composition. 


\section{CONCLUSION}

The toughness of the PLA was improved by blending with ENR and ENR-TPV. The $20 \mathrm{wt} \%$ of ENR composition was found to be the optimal composition that improves the toughness of PLA. The PLA/ENR-TPV blends showing better tensile strength, tensile modulus, elongation at break and impact strength than PLA/ENR blends. The SEM micrograph of PLA/ENR blends showed a cocontinuous morphology while PLA/ENR-TPV blends showed a dispersed ENR rubber particle in the PLA matrix.

\section{ACKNOWLEDGEMENT}

The author would like to thank the Universiti Teknologi Malaysia (UTM) and the Ministry of Higher Education (MOHE), Malaysia for funding this research under Fundamental Research Grant Scheme (FRGS/1/2017/TK05/UTM/02/4 / R.J130000.7846.4F978).

\section{REFERENCES}

Aghjeh, M. R., Nazari, M., Khonakdar, H. A., Jafari, S. H., Wagenknecht, U., \& Heinrich, G. (2015). In-depth analysis of micro-mechanism of mechanical property alternations in PLA/EVA/clay nanocomposites: A combined theoretical and experimental approach. Materials and Design, $88,1277-1289$.

Akbari, A., Jawaid, M., Hassan, A., \& Balakrishnan, H. (2014). Epoxidized natural rubber toughened polylactic acid/talc composites: Mechanical, thermal, and morphological properties. Journal of Composite Materials, 48(7), 769-779.

Auras, R. A., Lim, L. T., \& Selke, S. (Eds.). (2010). Poly(Lactic Acid): Synthesis, Structures, Properties, Processing, and Applications. New Jersey: John Wiley \& Sons.

Ebadi-Dehaghani, H., Khonakdar, H. A., Barikani, M., \& Jafari, S. H. (2015) Experimental and theoretical analyses of mechanical properties of PP/PLA/clay nanocomposites. Composites: Part B, 69, 133-144.

Gorrasi, G., Milone, C., Piperopoulos, E., Lanza, E., \& Sorrentino, A. (2013) Hybrid clay mineral-carbon nanotube-PLA nanocomposite films Preparation and photodegradation effect on their mechanical, thermal and electrical properties. Applied Clay Science, 71, 49-54.

Hassan, A., Wahit, M. U., \& Ching, Y. C. (2003). Mechanical and morphological properties of PP/NR/LLDPE ternary blend-effect of HVA2. Polymer Testing, 22, 281-290.

Ahmad, H. S., Ismail, H., \& Rashid, A. A. (2016). Tensile properties and morphology of epoxidized natural rubber/recycled acrylonitrile-butadiene rubber (ENR 50/NBRr) blends. Procedia Chemistry, 19, 359- 365.

Ismail, H. H., \& Akil, M. H. (2005). The effect of HVA-2 addition on the properties of PP-EPDM-NR ternary blends. Journal of Elastomers and Plastics, 55-72.

Kahar, A. W. M., Ismail, H., \& Othman, N. (2013). Properties of HVA-2 vulcanized high-density polyethylene/natural rubber/thermoplastic tapioca starch blends. Journal of Applied Polymer Science, 2479-2488.
Laurence, W. M. (Ed.). (2012). Permeability Properties of Plastics and Elastomers ( 3 ed.). USA: Elsevier Inc.

Li, W. C., Tse, H. F., \& 1., F. (2016). Plastic waste in the marine environment: A Review of Sources, Occurrence and Effects. Science of the Total Environment, 566-567, 333-349.

Mascia, L., Hawortha, B., Vignalib, A., Megnac, R., Aciernoc, D., \& Russod, P. (2016). Thermal transitions and solidification kinetics of poly(lactic acid) and blends with epoxidized natural rubber. Thermochimica Acta, 633, 82-90.

Mohamad, N., Zainola, N. S., Rahima, F. F., Maulodb, H. E. A., Rahima, T. A., Shamsuria, S. R., Manafa, M. E. A. (2013). Mechanical and morphological properties of polypropylene/epoxidized natural rubber blends at various mixing ratio. Procedia Engineering, 68, 439 - 445.

Moura, I., Nogueira, R., Veronique Bounor-Legare, \& V., M. A. (2012). Synthesis of EVA-g-PLA copolymers using transesterification reactions. Materials Chemistry and Physics, 134, 103-110.

Pongtanayut, K., Thongpin, C., \& Santawitee, O. (2013). The effect of rubber on morphology, thermal properties and mechanical properties of PLA/NR and PLA/ENR blends. Energy Procedia, 34, 888-897.

Saad, J. M., \& Williams, P. T. (2016). Catalytic dry reforming of waste plastics from different waste treatment plants for production of synthesis gases. Waste Management, 58, 214-220.

Tarinee Nampitch, \& Megaraphan, R. (2010). The properties of polymer blends between poly(lactic acid) and epoxidized natural rubber irradiated in the rubber phase. Proceedings of the 17th IAPRI World Conference on Packaging, Scientific Research, 388-389.

Thongpin, C., Kuttanate, N., Kampuang, K., \& Suwanwanit, N. (2012). Study of dynamic vulcanized PLA/ENR TPV filled with various organic modified MMT (OMMT). Journal of Metals, Materials, and Minerals, 22(2), 105-117.

Wang, Y., Chen, K., Xu, C., \& Chen, Y. (2015). Supertoughened biobased poly (lactic acid)-epoxidized natural rubber thermoplastic vulcanizates: fabrication, co-continuous phase structure, interfacial in situ compatibilization, and toughening mechanism. The Journal of Physical Chemistry B, 119(36), 12138-12146.

Xu, F., Ma, F., Hoch, M., Arnoldi, E., Cai, X., Dong, W., et al. (2016). Transparent blown films from poly (Lactide) and poly (ethylene-co-vinyl acetate) compounds: structure and property. Polymer Degradation and Stability, 129, 328-337.

Yang, Y., Tang, Z., Xiong, Z., \& Zhu, J. (2015). Preparation and characterization of thermoplastic starches and their blends with poly(lactic acid). International Journal of Biological Macromolecules, 77, 273-279.

Zhang, C., Wang, W., Huang, Y., Pan, Y., Jiang, L., Dan, Y., et al. (2013). Thermal, mechanical and rheological properties of polylactide toughened by epoxidized natural nubber. Materials and Design, 45, 198-205.

Zhang, N., \& Lu, X. (2016). Morphology and properties of super-toughened bio-based poly(lactic acid)/poly(ethylene-co-vinyl acetate) blends by peroxide-induced dynamic vulcanization and interfacial compatibilization. Polymer Testing, 56, 354-363.

Zurina, M., Ismail, H., \& Ratnam, C. T. (2008). The effect of HVA-2 on properties of irradiated epoxidized natural rubber (ENR-50), Ethylene Vinyl Acetate (EVA), and ENR-50/EVA blend. Polymer Testing, 27, 480 490 . 